\title{
Correction to: Assessing thermal acclimation of soil microbial respiration using macromolecular rate theory
}

Charlotte J. Alster (1) J Jasmine M. Robinson • Vickery L. Arcus •

Louis A. Schipper

Published online: 3 February 2022

(C) Springer Nature Switzerland AG 2022

Correction to: Biogeochemistry

https://doi.org/10.1007/s10533-021-00885-6

In this article incorrect versions of Figs. 2, 3, and 4 were published. The correct Figs. 2, 3 and 4 are shown below. The original article has been corrected.

The original article can be found online at https:// doi.org/10.1007/s10533-021-00885-6.

C. J. Alster $(\bowtie) \cdot$ J. M. Robinson ·

V. L. Arcus - L. A. Schipper

School of Science, The University of Waikato,

Hamilton 3240, New Zealand

e-mail: Charlotte.Alster@Waikato.ac.nz 

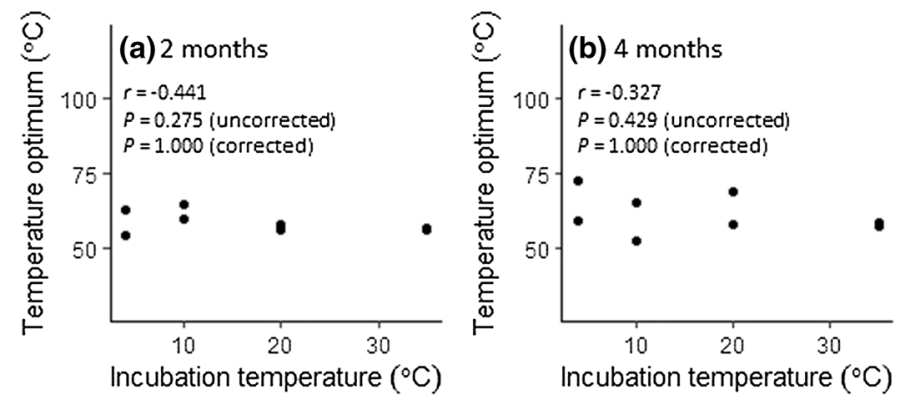

Incubation temperature $\left({ }^{\circ} \mathrm{C}\right)$
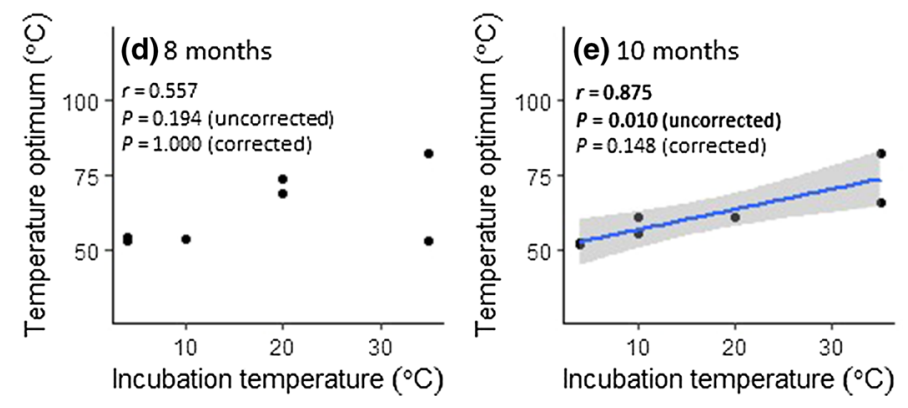

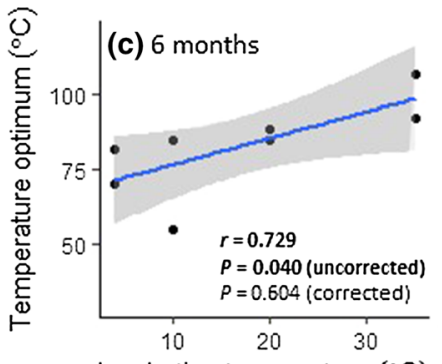

Incubation temperature $\left({ }^{\circ} \mathrm{C}\right)$
Fig. 2 Regressions between the temperature optimum $\left(T_{\text {opt }}\right)$ and incubation temperature at each measurement point. Lines indicate best fit with the $95 \%$ confidence interval shaded in grey for significant relationships. Both the uncorrected and Bonferroni corrected $P$-values are presented with bold text indicating significance $(P<0.05)$. Note, y-axes do not start at zero
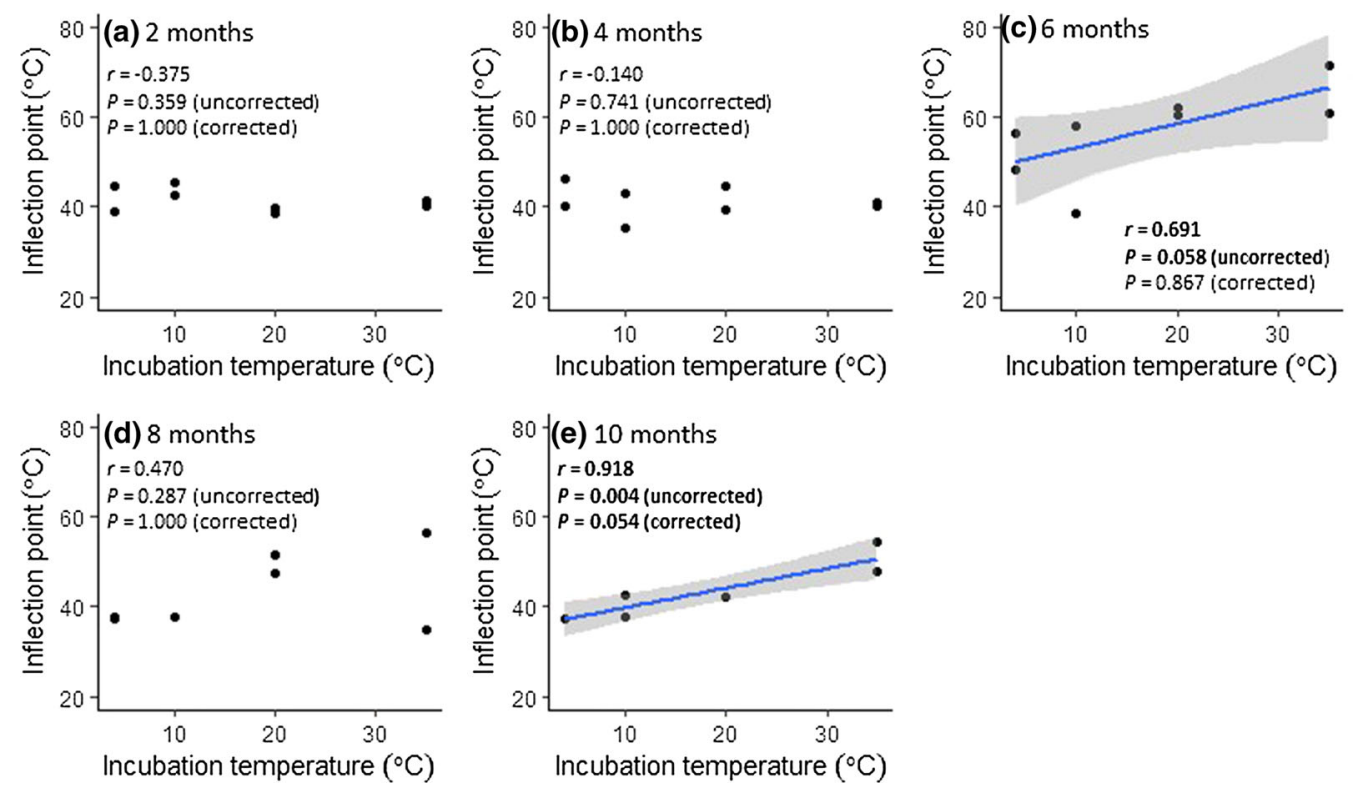

Fig. 3 Regressions between the inflection point $\left(T_{\text {inf }}\right)$ and incubation temperature at each measurement point. Lines indicate best fit with the $95 \%$ confidence interval shaded in grey for significant relationships. Both the uncorrected and
Bonferroni corrected $P$-values are presented with bold text indicating significance $(P<0.05)$ or marginal significance $(P<0.1)$. Note, y-axes do not start at zero 

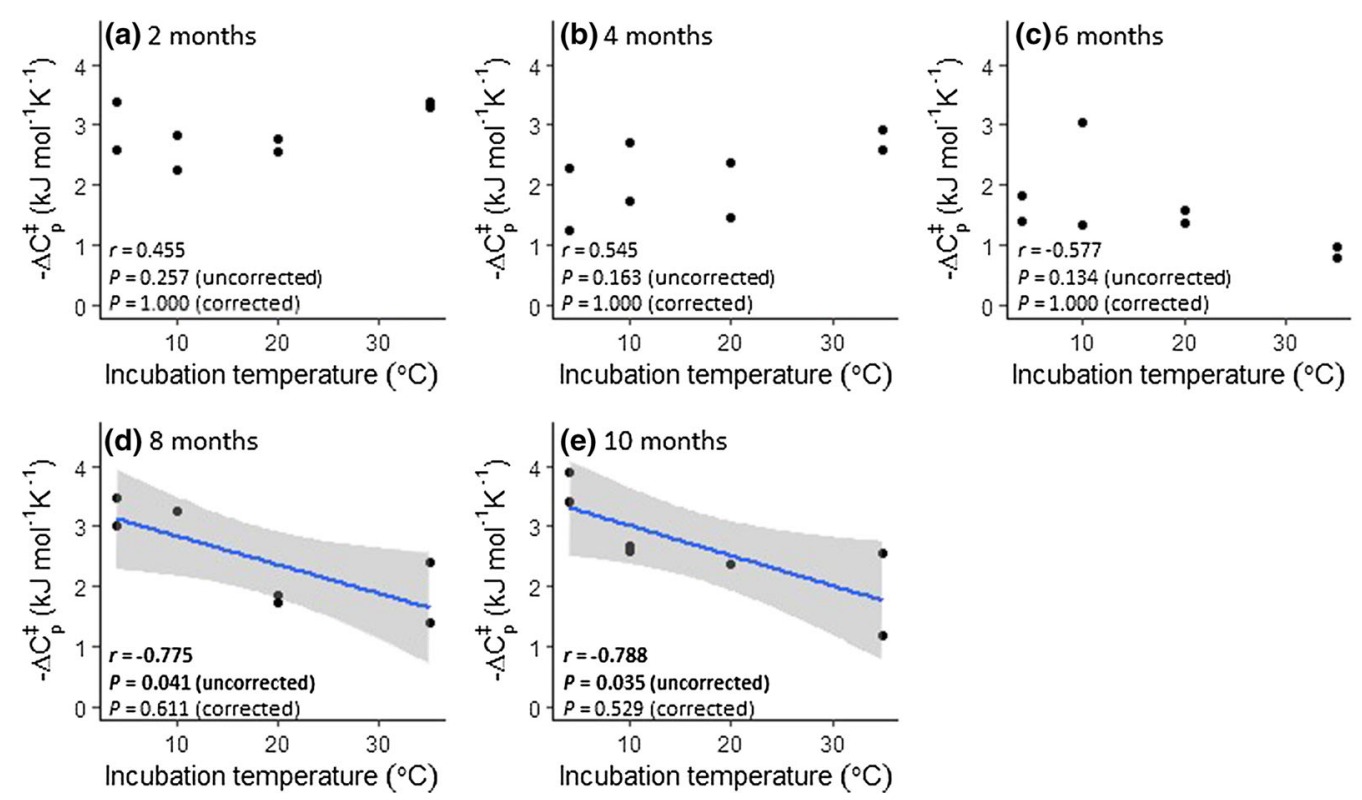

Fig. 4 Regressions between the heat capacity of the transition state $\left(-\Delta C_{P}^{\ddagger}\right)$ and incubation temperature at each measurement point. Lines indicate best fit with the $95 \%$ confidence interval shaded in grey for significant relationships. Both the uncorrected and Bonferroni corrected $P$-values are presented with bold text indicating significance $(P<0.05)$

Publisher's Note Springer Nature remains neutral with regard to jurisdictional claims in published maps and institutional affiliations. 